\title{
A Structured Approach for Display of the Most Practical Theories in ELT
}

Maryam Mohammadi Sarab (Corresponding author)

English Department, Najafabad Branch, Islamic Azad University, Najafabad, Iran

Email: maryam.mohammadi.sarab@gmail.com

Mohsen Shahrokhi

Department of English, Shahreza Branch, Islamic Azad University, Shahreza, Iran

Omid Tabatabaei

English Department, Najafabad Branch, Islamic Azad University, Najafabad, Iran

Received: $28 / 06 / 2020$

Accepted: $13 / 08 / 2020$

Published: 01/09/2020

Volume: 1 Issue: 3

How to cite this paper: Mohammadi, S. M, Shahrokhi, M, \& Tabatabaei, O. (2020). A Structured Approach for Display of the Most Practical Theories in ELT . Journal of Critical Studies in Language and Literature, 1(3), 36-55

DOI: https://doi.org/10.46809/jcsll.v1i3.27

Copyright (C) 2020 by author(s) and Global Talent Academy Ltd. This work is licensed under the Creative Commons Attribution International License (CC BY 4.0).

http://creativecommons.org/licenses/by/4.0/

\section{(c) (i)}

\begin{abstract}
A flowchart is just a diagrammatic approach to capturing and managing information. The present study investigates a structured approach to display some theoretical frameworks based on 'Computational Cognitive Model' by Dubey et al. (2008) and visual attention model proposed by Koch and Ullman (1985) and implemented by Itti, Koch and Neibur (1998). To this end, 10 practical theories are selected by the researcher to explain the sequence of steps followed by their framework. Since flowcharts may be used for diagnosing a malfunction or logic of solving a problem. This study can indicate the different parts of the theories to troubleshoot the problems as well as quick reference to previous steps. The researcher tries to get an agreement on confirmation of combinatory theoretical diagram from the 7 faculty members in Ruskin university of London. At the end of the statements, the exhibitive design of the practical theories selected in this study breaks complicated processes down into a series of smaller, more manageable steps. This schematically design can boost students' interests much better than text only and impart knowledge better since students can understand faster.
\end{abstract}

Keywords: Algorithmic Process, Combinatory, ELT, Flowchart, Theoretical Diagram, Theory

\section{Introduction}

A flowchart facilitates the visual capture of a process flow from start-point to end-point, with a developmental path of transition points, e.g. a manufacturing process. In research planning, you can also use it to work out a strategic process. Within a flowchart, each object follows the next step in the process from the previous represented parts. Diagrams are an efficient way of bridging the communication and semantics gap between designed parts and users. They are specialized flowcharts that sustain a substantial amount of information into a relatively labels and connectors.

The purpose of the present study is that based on given theory, the portions of the designed instructional flowchart are ordered by connecting the boxes with arrows. This diagrammatic representation illustrates things step by step visually, 
including lines and many vivid pictures showing flows and relations clearly. Flowcharts were used in analyzing, designing, documenting, or managing a process or program in various fields.

Reading all teaching theories as a whole might be quite daunting, developing and remembering what to present about each theory is much easier by depicting the portions of each theory. Therefore, teachers can break a teaching outline down into smaller sub-processes and students will "get the picture" of order flow at a glance from the flowchart. Then, one of the most effective ways is to use infographic materials to improve their interests is diagrammatic and algorithmic way in which each part is separately diagnosed.

If we do not use the information and data of our minds, it becomes difficult to access them after a while, not to be completely wiped out and destroyed. Displaying the instructions and the order of their execution in accordance with the algorithm reduces the probability of error occurring and missing each parts of the theory. This approach of study facilitates learners to experience and gains knowledge/skills they need in language learning process so that by using flowcharts, students are actively involved. The outline of the present study presents the inner and inherent knowledge of the specified theories for ELT. This outline constructs logic and flow of control of a program, method, theory, or subroutine and shows a set of conventional sections to display the instructions and the order of their execution according to the intended algorithm.

Students can identify areas for improvement and make precise perception for change; as well as they can use solutions, and check the possible result which is very helpful especially in working out the logic process map and workflow, before coding the theory process and the subsets of a theory framework. In this practical outline, there are a start and an end to specify the body of theory. For design of a flowchart, the researcher must be aware of the processes and procedures of that task. Students can concentrate more on theory concepts rather than all the nuances of a typical and ready-made function written just for implementation without having correct understanding of it. Students even can also run their programs directly in Flowgorithm or combine it to electronic devices. Once English language learning understand task or process logic to be easy for them to learn one of the major languages; therefore, Flowgorithm can interactively convert your flowchart to many languages.

This proposed designed diagram by the researcher can be to interact with the computer programs. An exhibitive instructional design contributes to the work process for improving and implementing the required models; therefore, total process of learning and teaching can be applicable in terms of achieving specific objectives (Branch and Merrill, 2012, p. 816). Based on Robinson, López and Tercedor (2006) statements, self-assessment takes enables and activates students to improve their own performance, realization, and responsibility for their learning. Thus, the students will have a positive perception of the new learning/teaching design which is responsible for increasing important aspects of the translation process. Visual illustration in training steps would be much more effective than any written tools explained.

Process maps as a measurement tool which is very necessary to manage, serve, and improve teaching process. A process map for a detailed flowchart that is a useful tool for auditing a process has four steps as follows:

1. "Identifying and understanding the steps in a process.

2. Gathering information to identify the objectives, risks and controls in a process.

3. Interviewing the individuals involved and creating the process map.

4. Analyzing and effecting changes to improve the process" (Burlton, 2015; SmartDraw, LLC, 1994-2019).

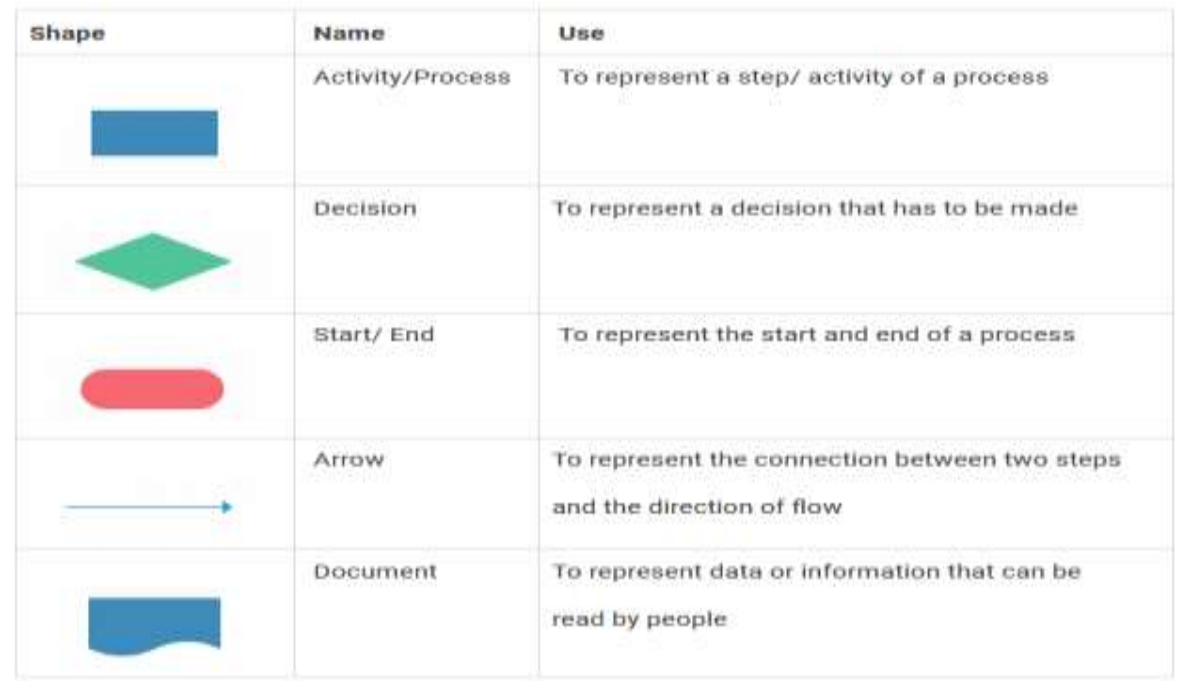

Figure1.1 Creately blog', visualize ideas, concepts, plans or processes

The nature and complexity of a theory can affect structure of its diagram. To implement a flawless diagram, the researcher must focus precisely on the points of body of theory. 


\section{ELL Purposes}

- Provide appropriate education in an accepting environment;

- Provide English language development based on accepted theory;

- Promote the diversity in languages;

- Advocate for community responsibility and involvement;

- English proficiency for success in society;

- Appreciation of unique attributes of students from linguistically backgrounds;

- Access to all educational programs and curricula.

An applicable tool can clearly define the teaching method along with the qualified theories by a comprehensive diagrammatic design in which the goals, procedures, and tactics are planned as an instructional rule-based guideline. The aim of the researcher is forming engagement objectives, namely, specifying of selected theories for accomplishing according to define theory framework. A theoretical framework for thinking about coherence of components between learning process structure and other aspects of linguistic can promote the representation of meaning for each event or instruction. The existing patterns of semantic constructions in each theory reveal the organization of the semantic system under investigation. It is likely to want be the total goal of the computational models of skill acquisition as acquiring the ability to solve problems. According to the purpose of the present study, learners can "make inferences related to events occurring in the world and realize statements about them to be produced" (Ohlsson, 2008) [Input/Output: Start/End]. The designed theory-based flowcharts are visual, revisable, and reversible to cover the initial stages of learning in terms of a principle or rule governing the theory. They increase speed and accuracy in practice.

\section{Theoretical Basics}

\subsection{Types and Uses of Flowcharts}

The wide variety of flowchart types which are more commonly used:

- "Swimlane flowcharts

- Data flow diagrams

- Influence diagrams

- Workflow diagrams

- Process flow diagrams

- Yes/no flowcharts

- Decision flows" (SmartDraw, LLC).

The steps of the theories are organized in a sequential order. Theory diagram can be identification process as a symbolic one. The following options are the efficiency of design of a flowchart:

- Planning a new project

- Documenting a process

- Modeling a business process

- Managing workflow

- Auditing a process

- Mapping computer algorithms

- Data management

- Chemical and process engineering ${ }^{2}$

\subsection{Theory Framework}

The researchers defined the essential different issues in relating to theory learning and to information applications/resources which contain enough knowledge and theory-based information. Vygotsky's influential theory considered children to learn best by social interactions with others such as parents, caregivers, teachers, and even peers for making their perception of the world around them. According to Vygotsky, when children interact with more knowledgeable helpers, they can promote the ability first to talk and think about new information, and to understand and apply it in new situations (Cameron, 2001). A theory of teaching, in harmony with your integrated understanding of the learner and of the subject matter to be learned, will point the way to successful procedures on a given day for given learners under the various constraints of the particular context of learning. In other words, your theory of teaching is your theory of learning "stood on its head." (Brown, 2000, p. 19).

Brooks (1960) wrote, "the single paramount fact about language learning is that it concerns, not problem-solving, but the formation and performance of habits" (p. 49); according to this fact, repetition as an element of reinforcement helps the habit formation. Rules are indicative of behaviours to motivate the learners in terms of their ability and responsibility in their tasks. In both stimulus and response, if the learner's response is correct, something gets mentally right acts. Then, the learner will further nourish repeating the correct answer (similar to using a constant plan for practicing and imitating to dominate it or a simulation of a designed program. Coder (1967) suggested that it was more important that L2 learners be interested in finding out their own errors, rather than be corrected by the teacher; error correction by learners plays an important role to guide, motivate, and encourage students to enhance their accuracy in second language (L2) learning. Davis (1997) suggested that the design and selection of teaching methods is important not only the nature of the subject matter but also how students learn. 
The theoretical environment is restricted to formal educational activities. There are three elements which play a key role in a) the level of cognitive and deep processing of information, b) connecting to existing mental models in long term memory, and c) accessible cognitive resources that make the students' engaging in more meaningful activities and actively process the information with existing knowledge (Wittwer et al. 2010, p. 74).

\subsection{Diagrammatic Instructional Scheme}

The flowchart sections of this design were depicted based on the theory objective of the present study. 10 theories in teaching/learning process are practically selected and labeled in each section based on theory requirements. Algorithm is formulated as a flowchart according the same selected teaching theories.

Gane (1972) designed an algorithm as a responsible training tool for certain training modules. Learning environments will develop an instructional design for improving acquisition of knowledge and skill by students in a theoretical and practical research in the different areas of cognition, education, decision-making, and problem solving. The instruction based on specific behavioral aims indicates the systematic instructional design of models such as the 'Computational Cognitive' model of instructional outline.

Flowchart drawing:

- Identify= input and output

- Apply= reasoning skills to solve the problem, decision making, promoting motivation, and turning easy between desired and intended parts.

- Draw = the flowchart using the appropriate symbols, directions, and arrows to show the sequence of steps respectively in solving the problem.

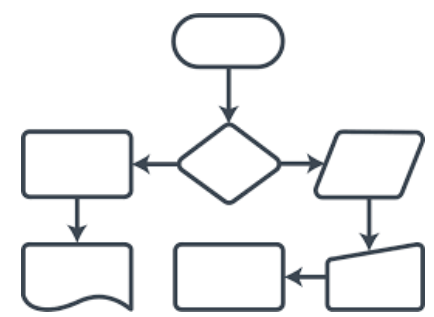

The following diagram shows the goals of this study:

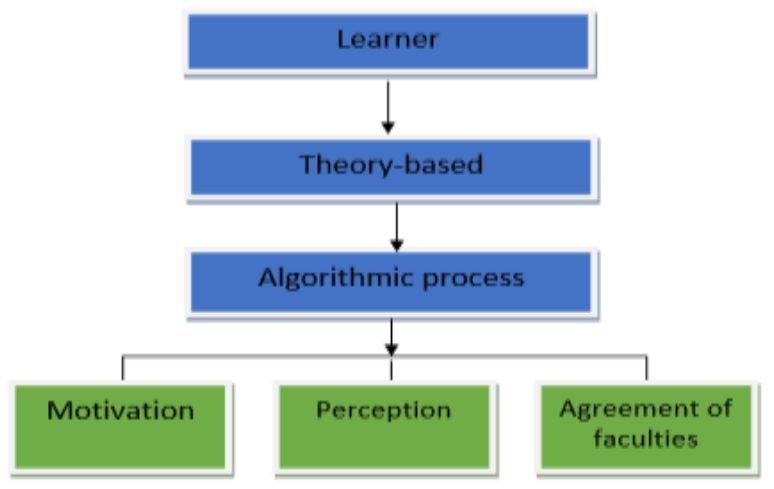

Figure 2.1 Basic modules of electronic feedback 


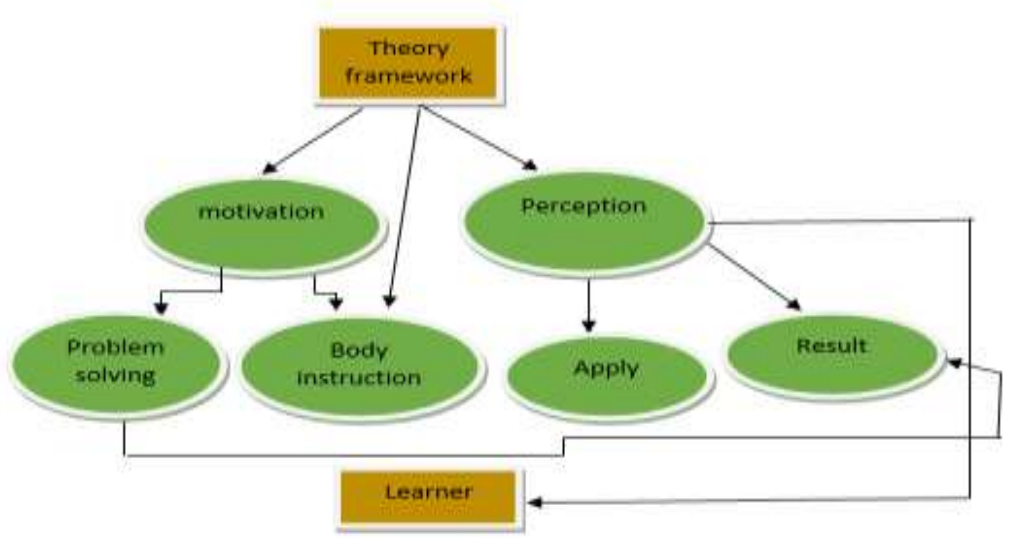

Figure 2.2 The diagram of the whole of the study goal

\section{4. 'Computational Cognitive Model' (CCM) of visual attention}

CCM generates the concepts of succession, duration, continuity, immediate present duration, and lengths of time. This model helps learners for understanding situations and detecting similarities, changes, as well as cause-effect relations between elements in the theory. This model helps how they change over time. Similarly, CCM can account for the future, even create expectations that represent possible future states based in real life (Snaider, McCall, and Franklin, 2012). A 'computational cognitive model' extracts the various cognitive functionalities through developing elaborated, process-based perception for characterizing corresponding computation models (Meng and Sen, 2017). Meng and Sen (2017) indicated that CCMs "are mostly process based theories i.e., they try to answer how human performance comes about and by what psychological mechanism and are used to do tasks that are hard or impossible to do" (p: 1).

To provide qualitative and quantitative stimulation of theories for explaining, identifying, and showing the functioning of the human mind and also theoretical similarities, CCM has a significant role. CCMs can simplify the hard tasks; thus, it is based on the specific routine of doing something. The valid theories of cognition are constituted by computational models of cognition. A number of theories relevant to visual attention can be used and implemented in computational models (De Pisapia, Repovs, and Braver, 2008, p. 5).

Visual attention models can indicate the benefits in understanding of the architectural structure of the visual plan to enable the design of computational models similar to the known neurophysiology of vision for matching a wide variety of neurophysiological findings in accordance with motivational/behavioral results coming from the basic experimental paradigms and the critical constructions such as emotion, motivation, and consciousness. "Any comprehensive theory of attention will need to address how attentional mechanisms are modulated by internal estimates of value" (p. 51). Attention can quickly detect and choose any aspect of the visual environment (De Pisapia, Repovs, and Braver, 2008, p. 4).

In cognitive neuroscience terms, the maps are for coding the specific properties of visual input; they visually display the various stages of analysis of what stream. 


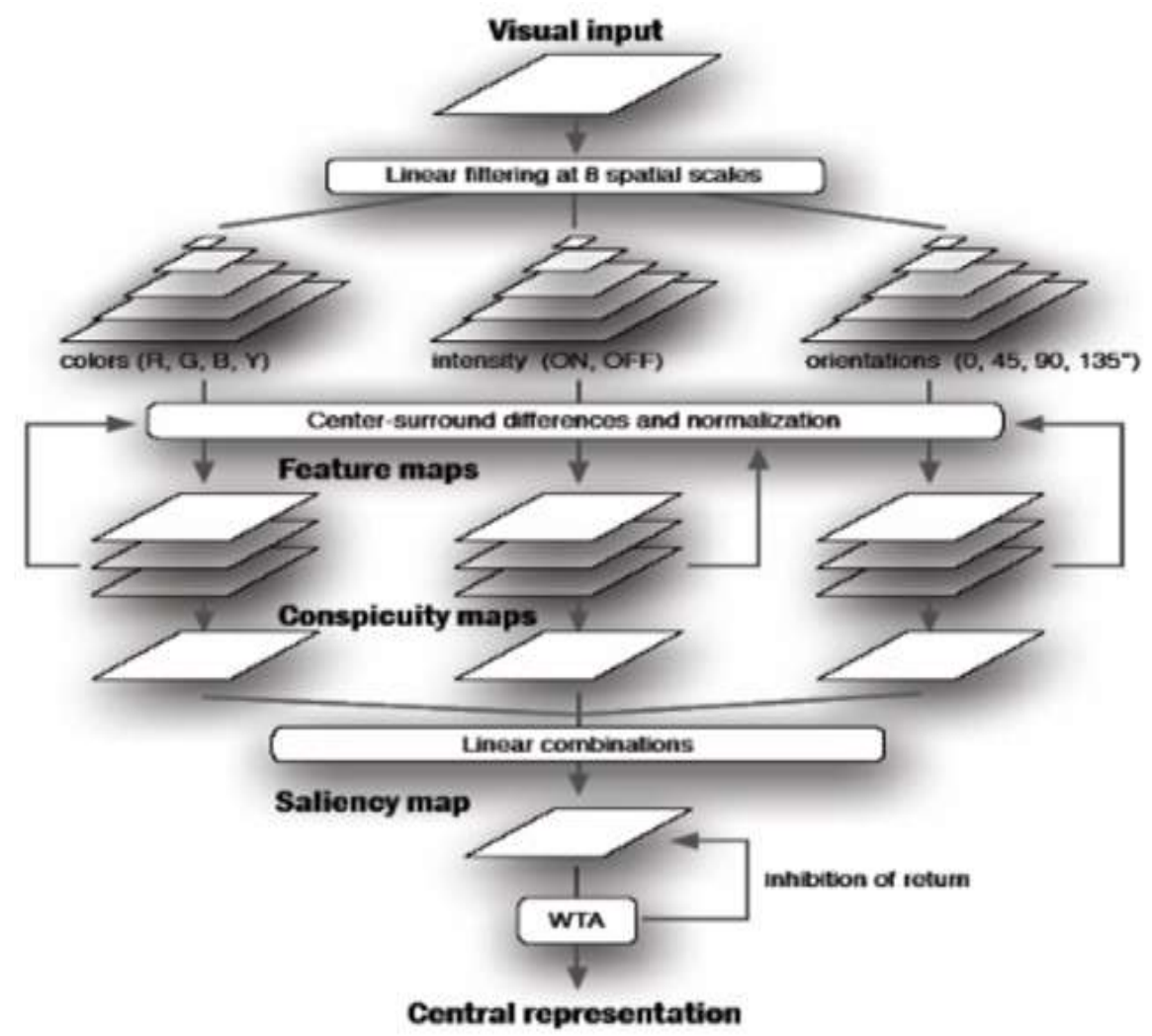

Figure 2.1 Saliency map based computational model of visual attention

\subsection{Selected Teaching Theories}

1. Cognitive theory

Students' prior knowledge is integrated to use and promote meaningful communication not just teaching points in each unit separately.

• "Use of headlines, especially at lower levels ("coffee or tea?" rather than "What would you like to drink?").

- Giving importance to cultural and individual differences (Çelik and Erbay, 2013).

- Involving parents in their children's language learning to extend foreign language learning to home life (Enever, 2011).

- Making use of internet technology as much as possible due to its familiarity to many learners and its demonstrated educational benefits" (Bruner, 1960, p. 10).

2. Transformational generative grammar theory

Learners do not acquire an endless list of rules but a limited set of transformations which can be used over and over again.

3. The theory of language underlying Audioligualism

Which was based on the structural linguistics. Learning a language entails mastering the elements or building blocks of the language and learning the rules, by which these elements are combined, from phoneme to morpheme, from morpheme to word, from word to phrase, and from phrase to sentence.

4. Audioligualism theory based on behaviorism

- It considers that a human being can be trained by a system of reinforcement.

- The human beings are able to show behaviors.

- These behaviors are based on the stimulus given to them.

- Correct behavior receives positive feedback while errors receive negative feedback (Skinner, 1957).

5. Vygotsky's theory

To gain a perception of Vygotsky's theory on cognitive development, students must realize two of the main principles of Vygotsky's work; namely, the More Knowledgeable Other (MKO) and the Zone of Proximal Development (ZPD). The aim is learner can be "close" to mastering (McLeod, 2018).

6. Constructivism theory

It refers to that people are responsible for making their own understanding of the world and utilizing what they know based on the previous experiences by linking new information to the same experiences. Therefore, people can use these experiences and new information for constructing their own meaning. 


\section{Input hypothesis theory}

Children can learn language and applied it to adult language learning using Input Hypothesis proposed by Krashen (1985); learners use the comprehensible input to deduce rules which is beyond the learner's present proficiency. He states that language is gained by using comprehensible input.

8. Complexity theory

It is with describing and tracing emerging patterns in dynamic systems for explain change and growth. This theory is the spontaneous occurrence of something new which arises from the interaction of the components of a complex (LarsenFreeman, 2013).

9. Connectionism theory

It likens the brain to a computer that would consist of neural networks: complex clusters of links between information nodes. These links or connections become strengthened or weakened through activation or non-activation. Learning precisely occurs on the basis of associative processes. The human mind has associations between elements and creates links between them; they also become part of larger networks as connections between elements become more numerous.

10. Theory of learning

- To teach oral proficiency at a beginning level

- Comprehension is a means to an end.

- To teach basic speaking skills as the final goal

- To produce Ss who can carry out an uninhibited communication understandable to native speakers

- The above goals must be obtainable via the use of action-based drills in the imperative form.

\subsection{Selected Teaching/Learning/Language Theories Flowchart/Diagram}

1. Cognitive theory

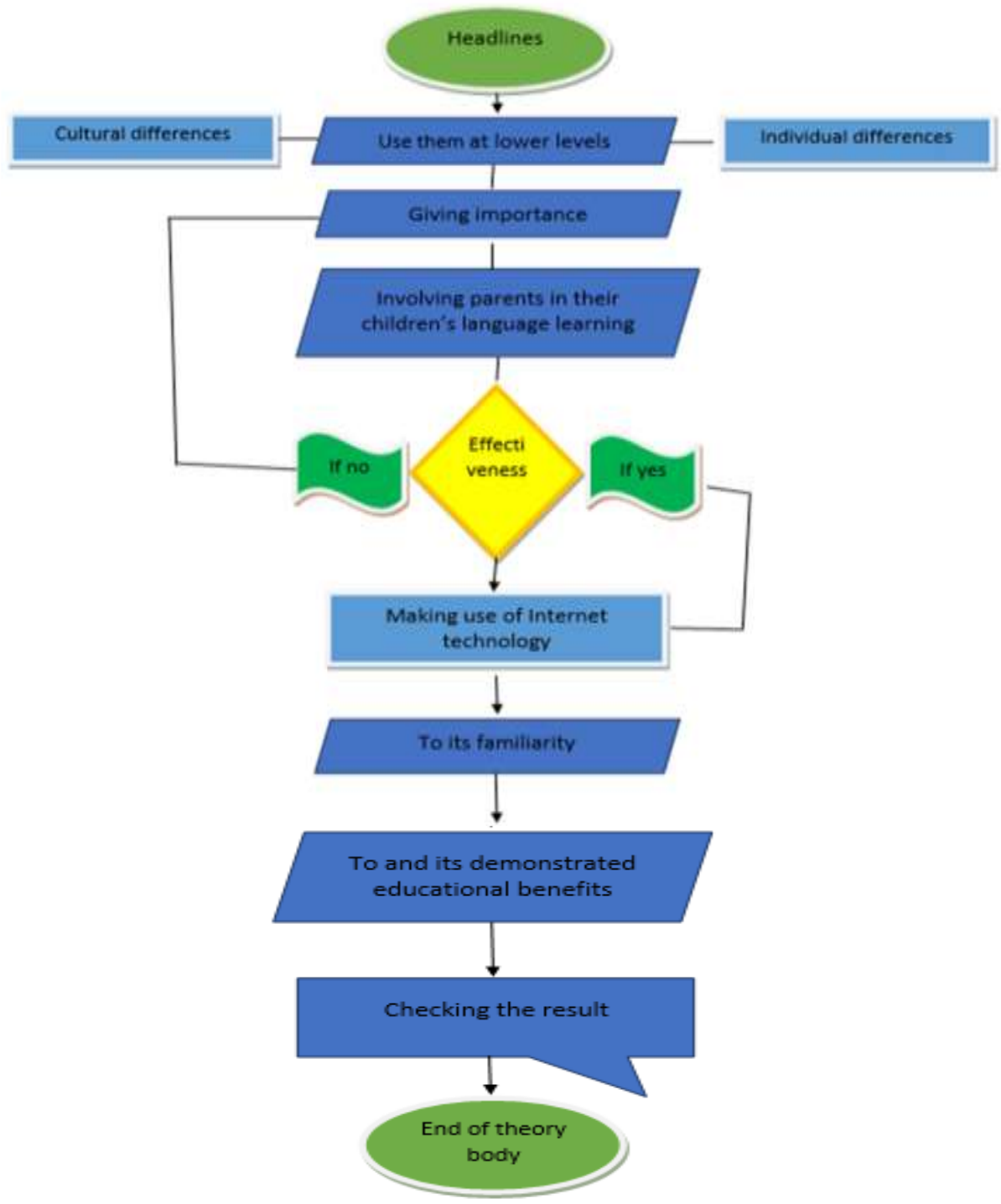

Figure 2.1. The designed algorithm of the teaching cognitive theory 
2. Transformational generative grammar theory

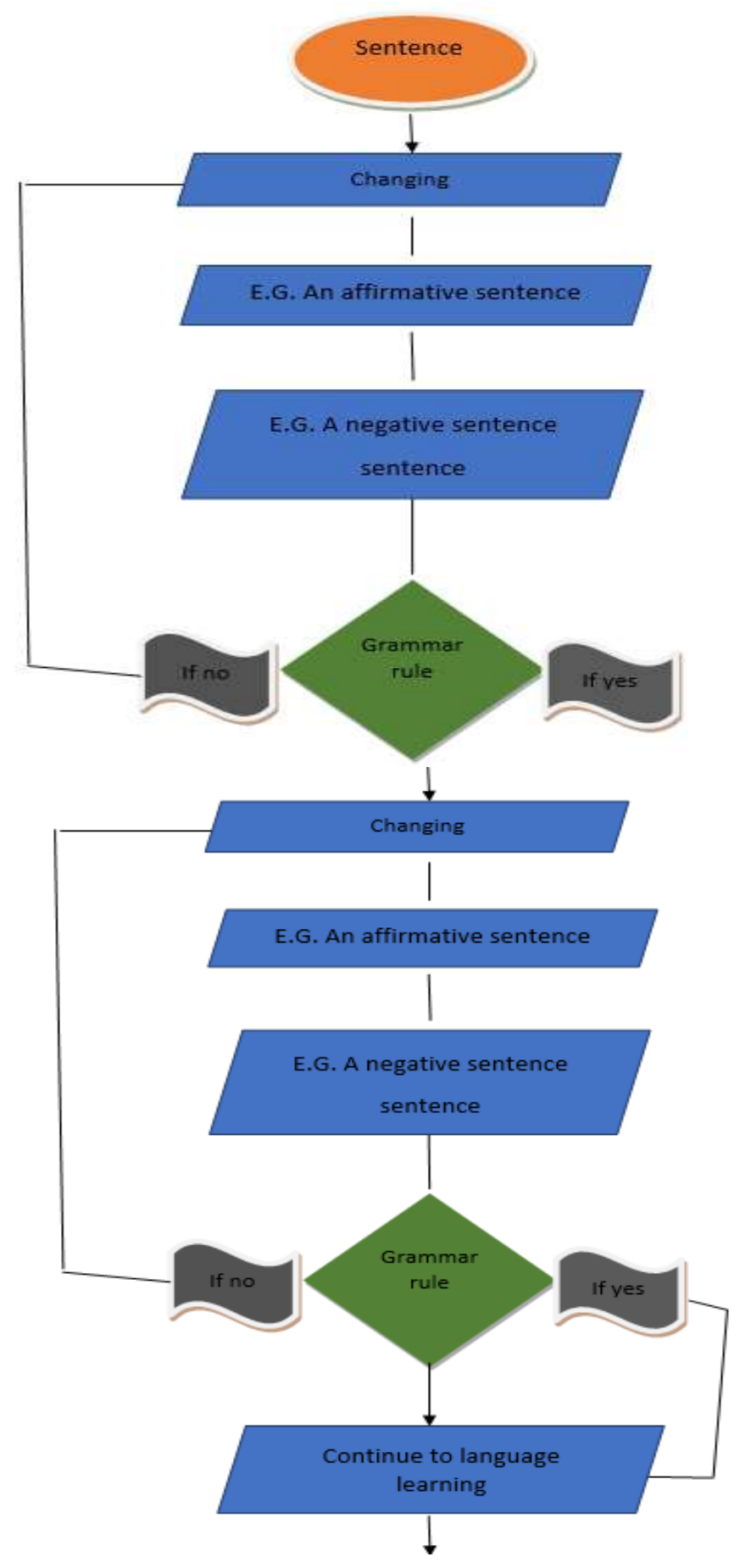




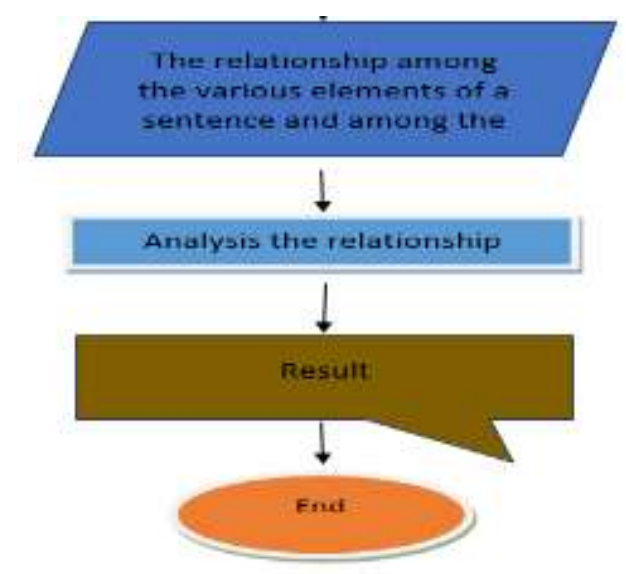

Figure 2.2 The designed algorithm of the teaching TGG theory

3. The theory of language underlying Audioligualism

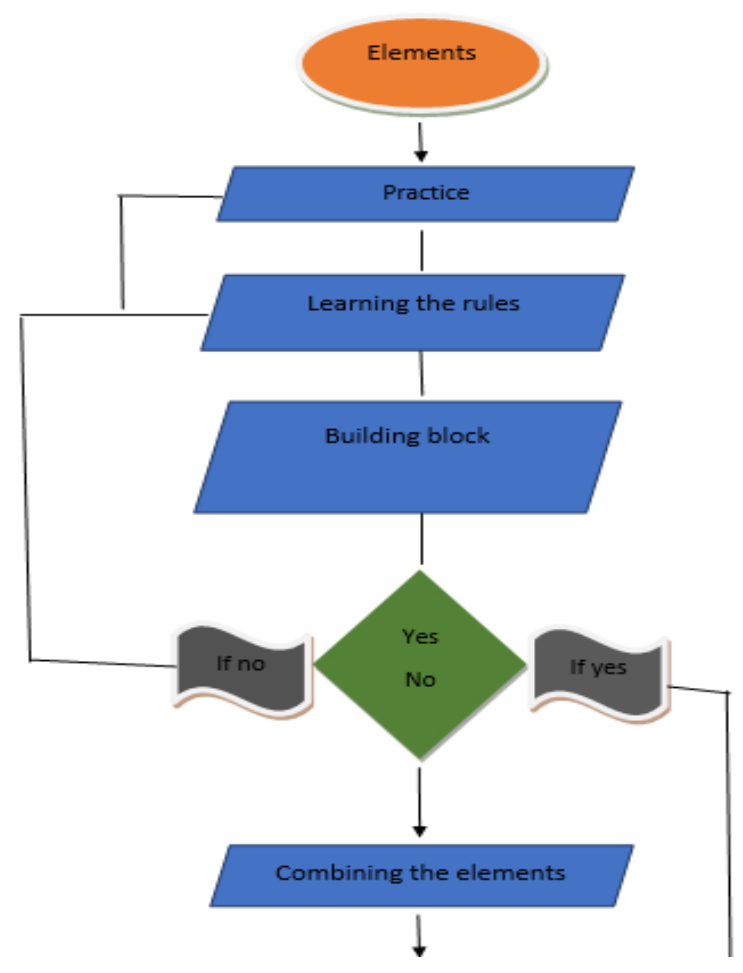




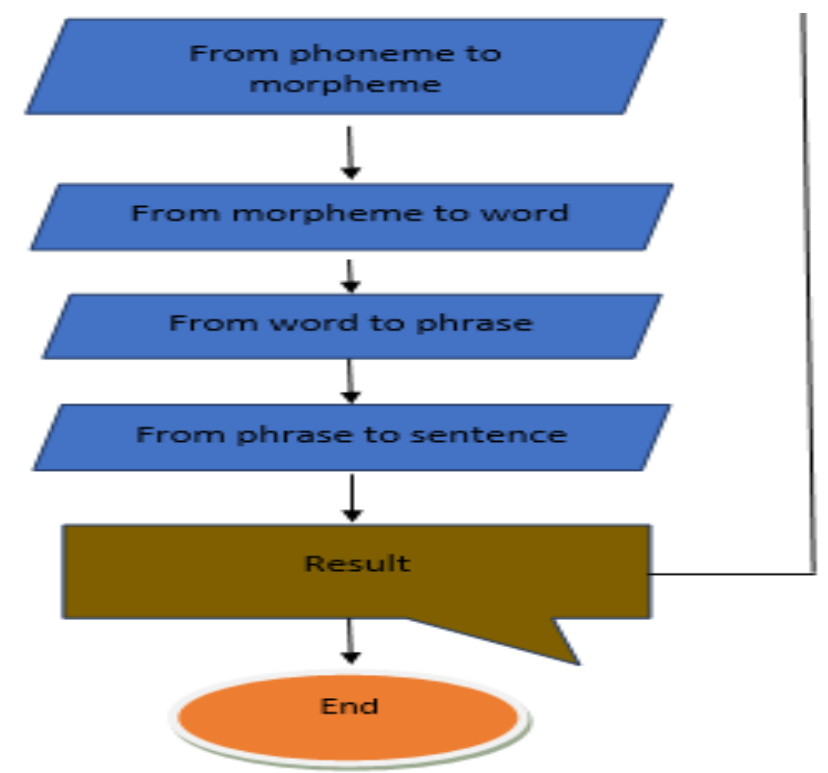

Figure 2.3 The designed algorithm of the Audioligualism theory based on behaviourism 4. Audioligualism theory based on behaviorism

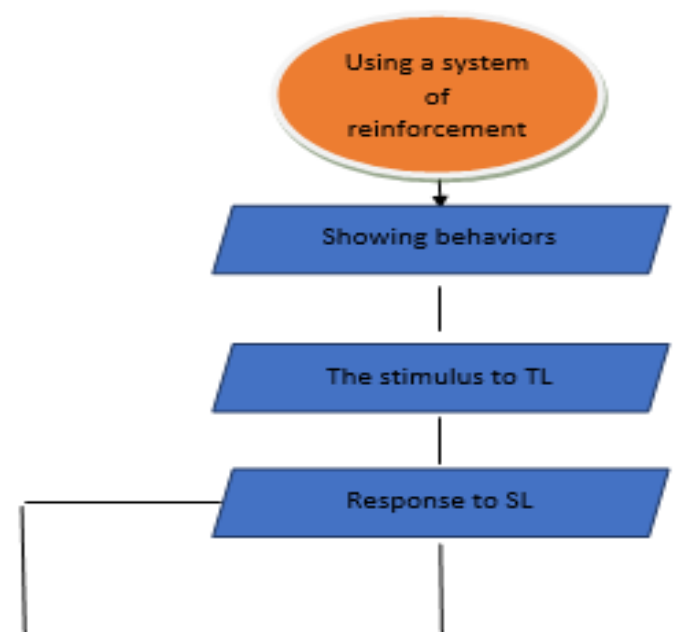



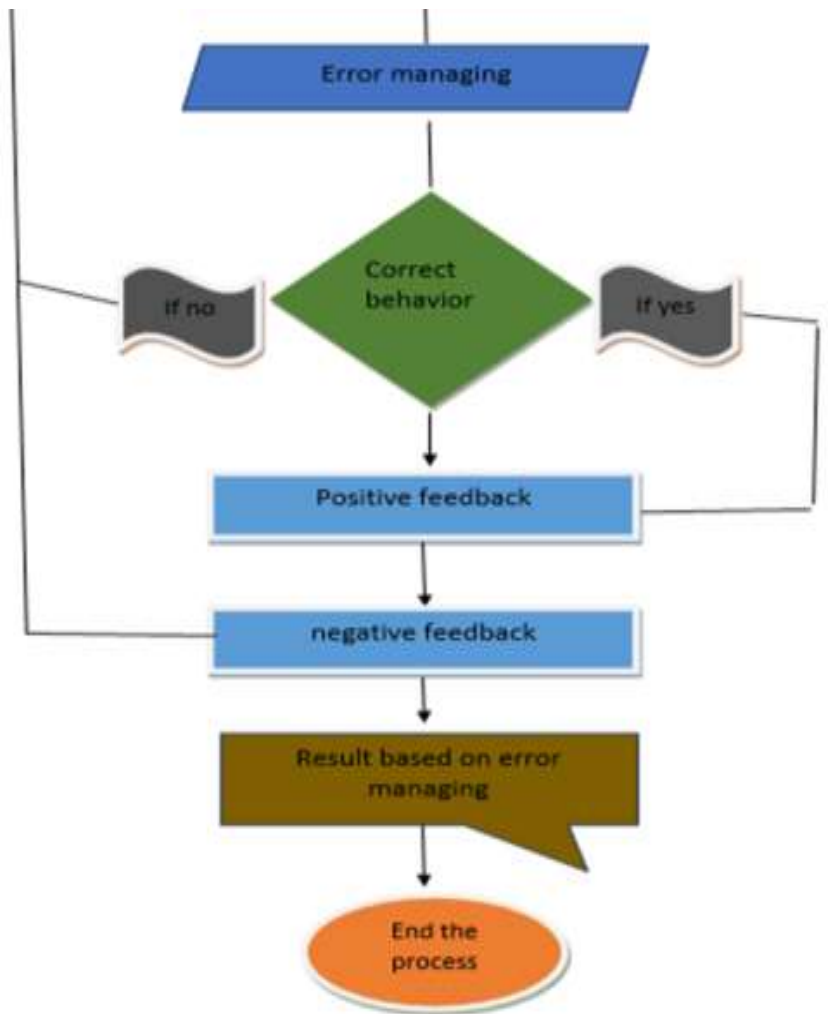

Figure 2.4 The designed algorithm of the Audioligualism theory based on behaviorism

5. Vygotsky's theory (Zone of Proximal Development (ZPD))

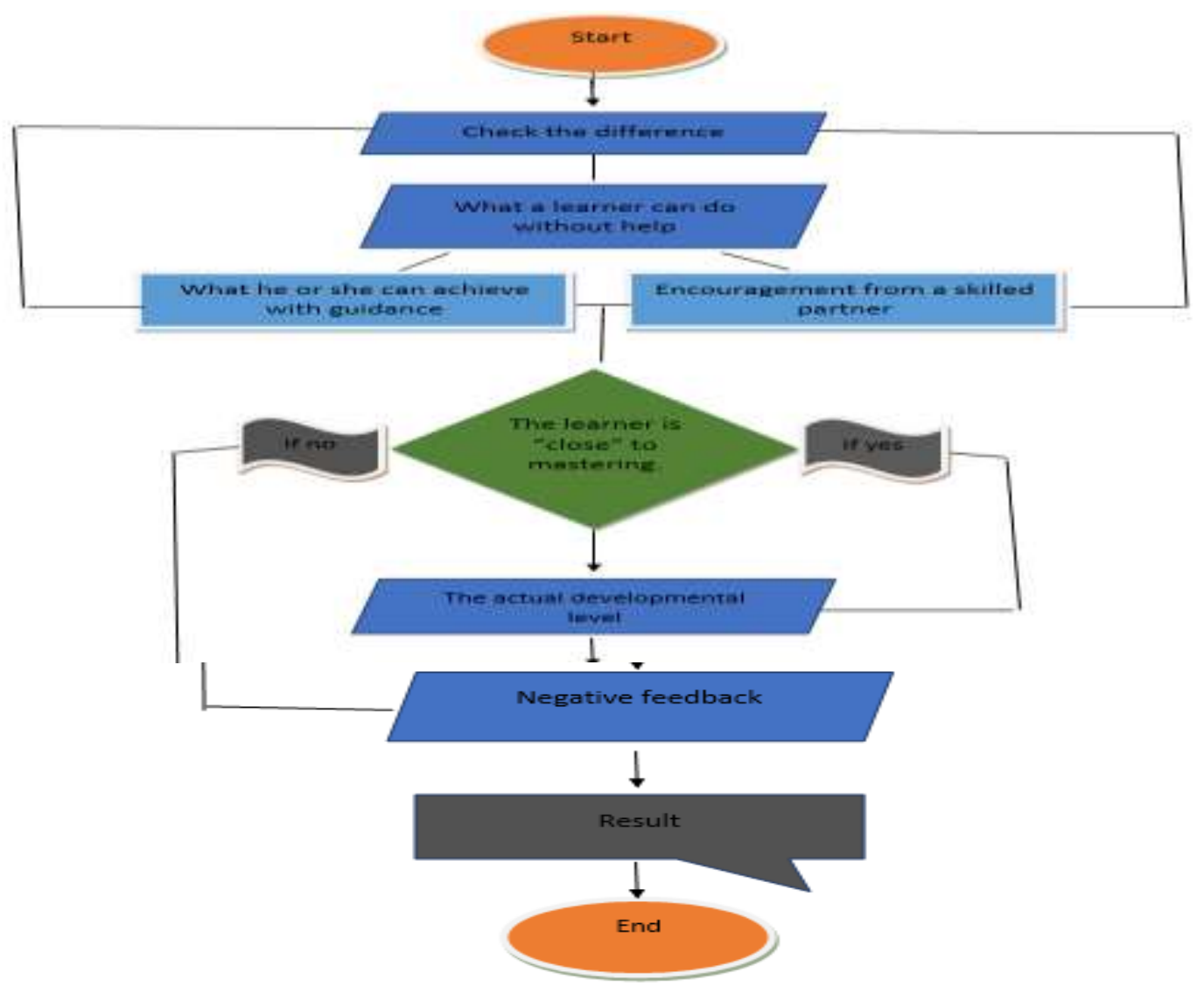

Figure 2.5 The designed algorithm of the ZPD theory 
6. Constructivism theory

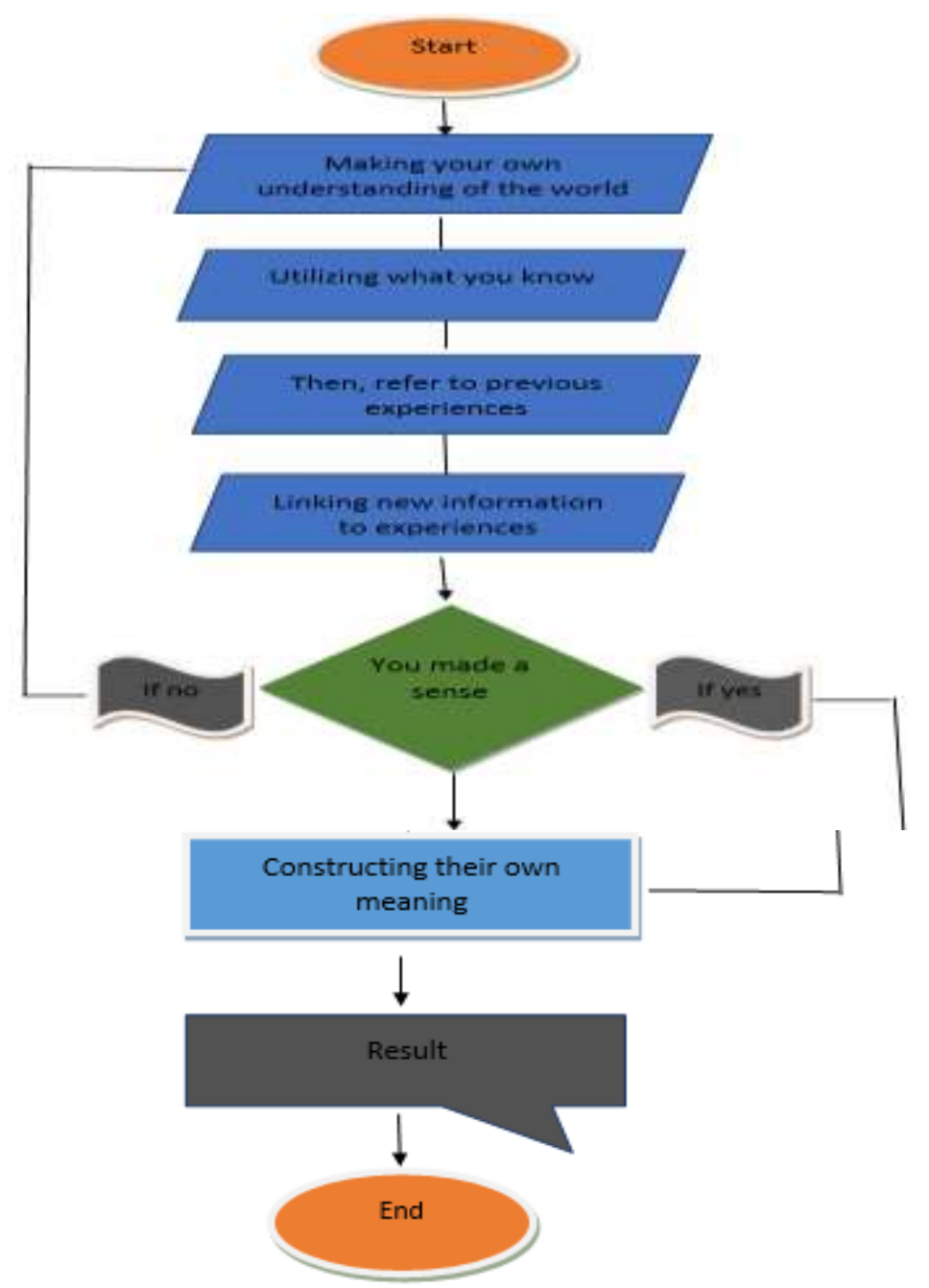

Figure 2.6 The designed algorithm of the constructivism theory

7. Input hypothesis theory

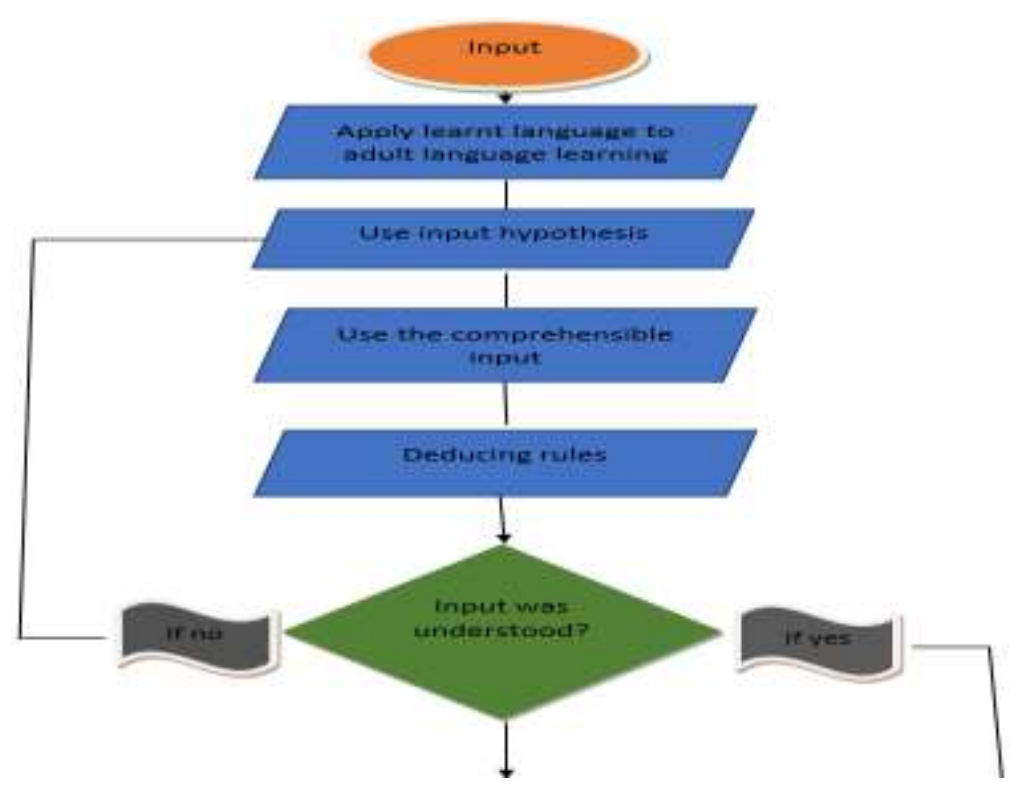




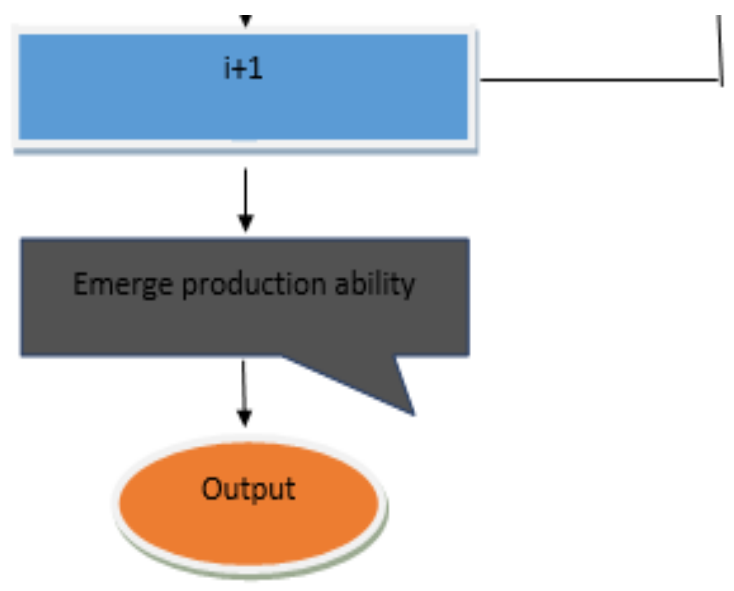

8. Complexity theory

Figure 2.7 The designed algorithm of the Input hypothesis theory

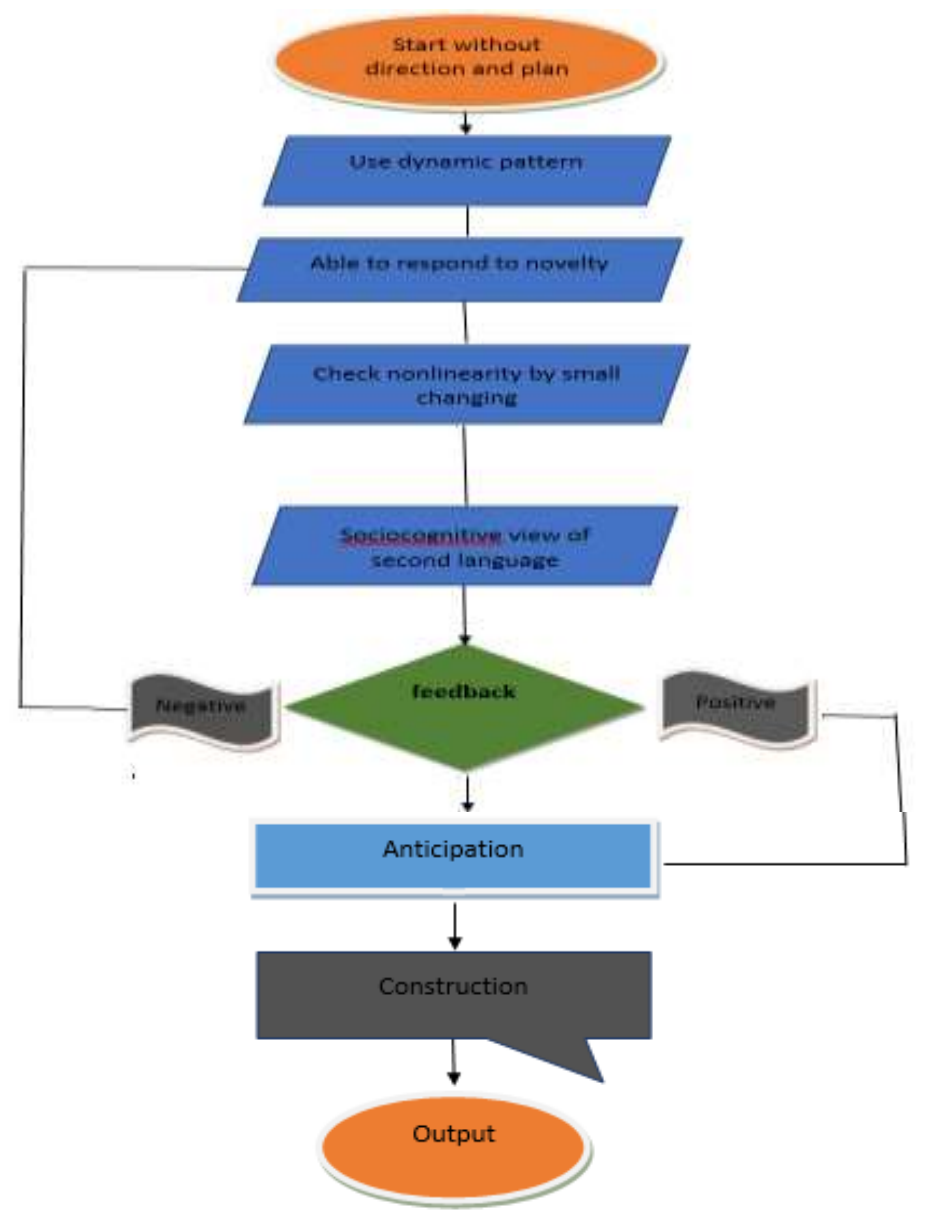

Figure 2.8 The designed algorithm of the complexity theory 
9. Connectionism theory

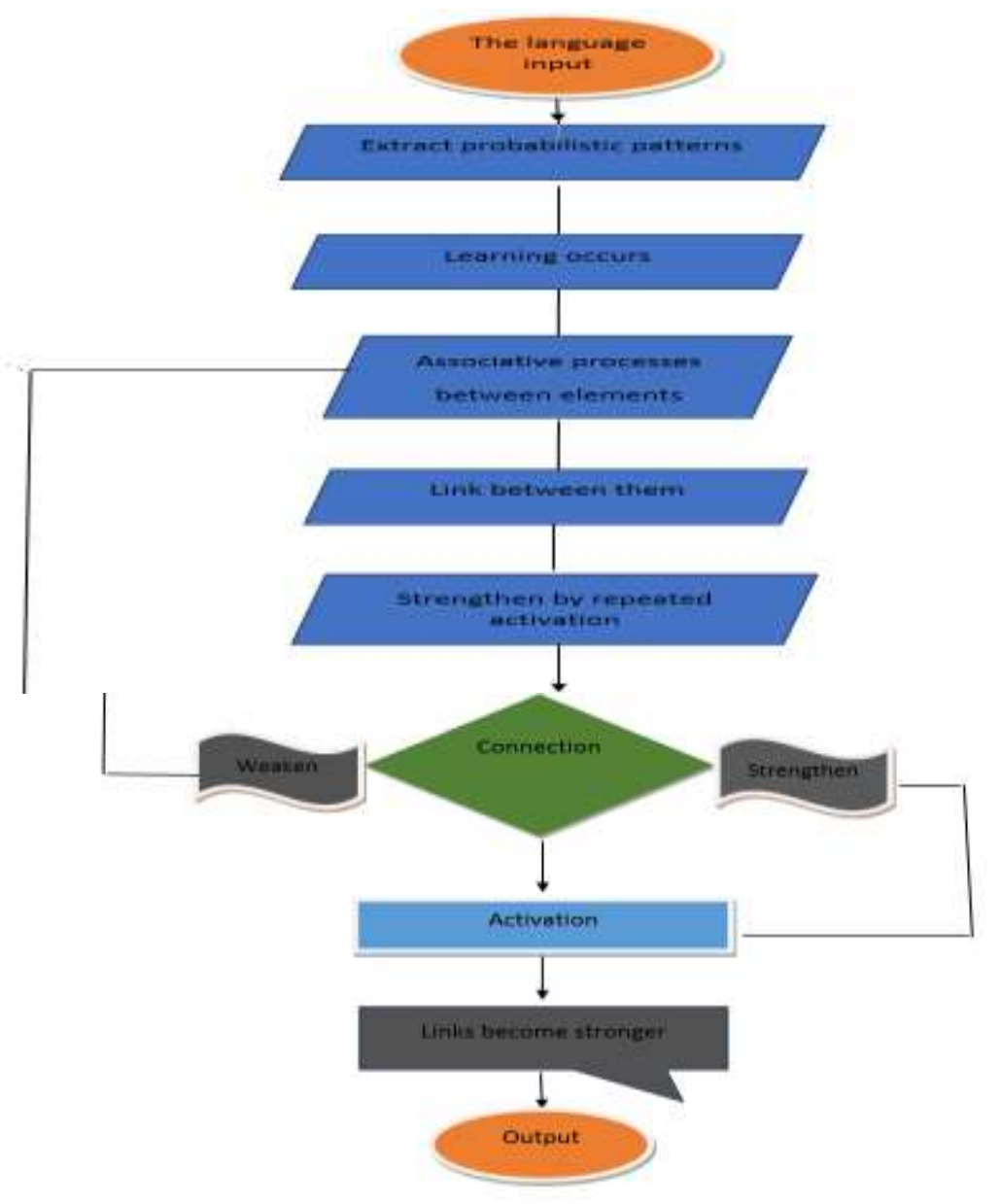

Figure 2.9 The designed algorithm of the connectionism theory

10. Theory of learning

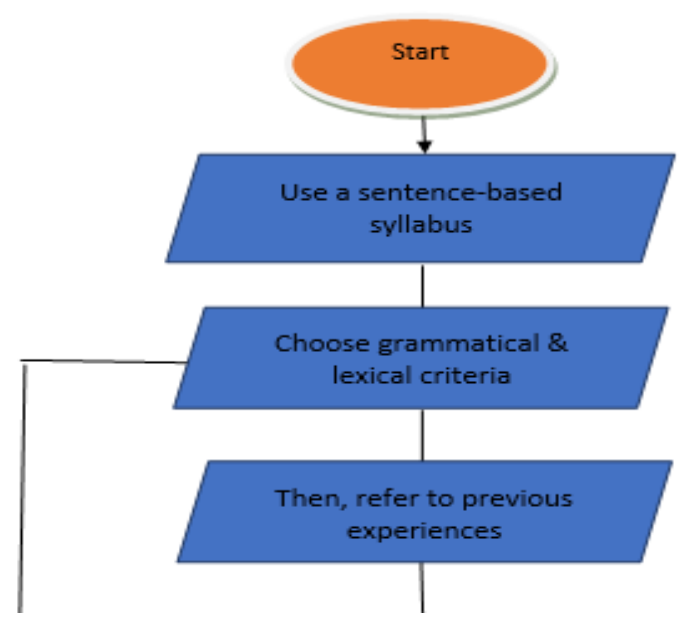




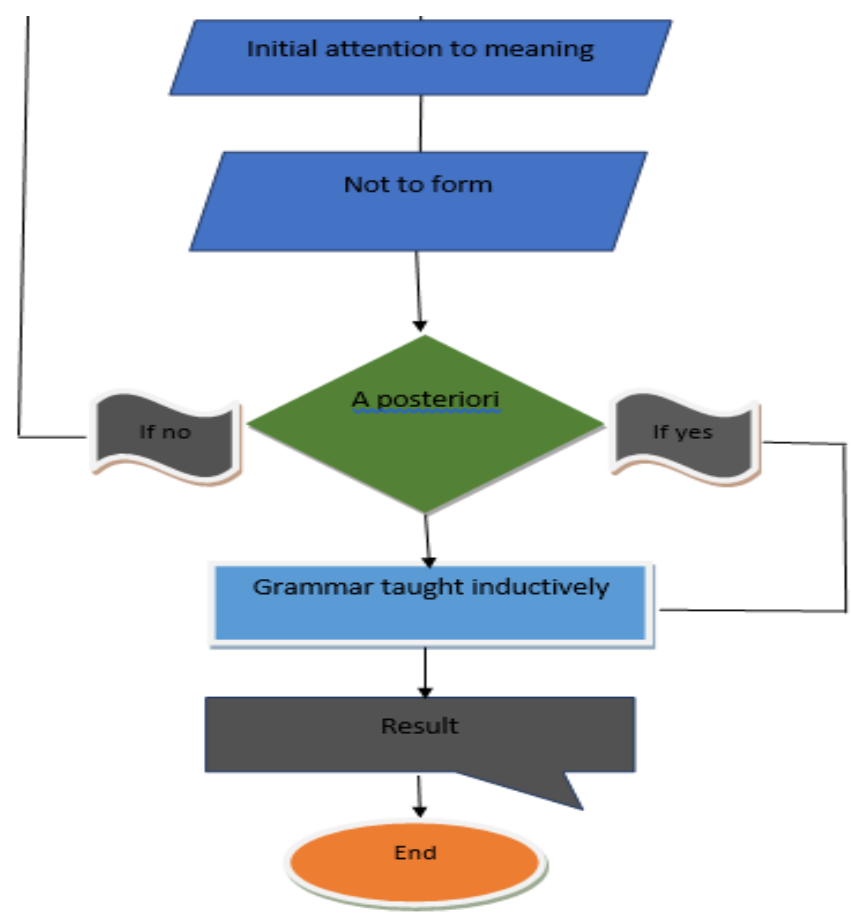

Figure 2.10 The designed algorithm of the theory of learning

\section{Methodology}

\subsection{Introduction}

The procedural outline and the objective design of the study is specified in this section.

\subsection{Participants}

The researcher is going to strategize the using of theory as visually specified and outlined model. This design aimed to create motive and interest from understanding the theories content to make useful outline on improving students' performances and perception.

A six-person team consists of faculty members of English language department to get an agreement with combinatory theoretical flowchart based on the theories selected by the researcher. To do this, a questionnaire was designed by the researcher for investigating the experienced faculties' comment with respect to their students' proficiency and performance using this outline.

\subsection{Instruments}

The contents of the diagram can be electronically or manually formed for administrating the relations of the labels. The researcher used the manually way to display the needed relations of the sections; these sections were linked together to indicate the whole framework of the specified teaching theories.

\subsubsection{Questionnaire}

The researcher used a questionnaire via Question Mark $^{3}$ and Smart Survey ${ }^{4}$ an online questionnaire in a few steps. Before creating the questions, it is need to create the topic structure that will store your questions. The stages of creating a questionnaire:

- Creating a topic

- Choosing a question type

- Creating a question

- Trying out a question

3.3.2. The list of selected teaching theories

1. Cognitive theory

2. Transformational generative grammar theory

3. The theory of language underlying Audioligualism

4. Audioligualism theory based on behaviorism

5. Vygotsky's theory

6. Constructivism theory

7. Input hypothesis theory

8. Complexity theory

9. Connectionism theory

10. Theory of learning 


\subsection{Procedure}

To illustrate a significant effect on a specific designed instructional flowchart based on 'Computational Cognitive' model of visual attention, six professors who are specialist in the field of language teaching, evaluate the learning level of the student by filling in a close ended questionnaire. The present study is going to investigate whether this designed diagram will contribute to the students' performance and perception or not.

The use of a regularly training theory-based diagram distinguishes the present study from others. The diagram related to each theory content is drawn to the training flowchart/diagram that can be utilized by ELLs easily. To get the reliability of the given design, six faculty members must reach an agreement on confirmation of diagram; then, the researcher will go forward with a correlation table by SPSS for the participants of the study. The questionnaire was administrated to meet the expectations of the researcher.

3.5. Research design

To draw an executive design for theory-based algorithm for ELT procedures, an expert team including six faculty members in Ruskin university in London, England investigates instructional flowchart which its parts are connected together. The researcher intends such design so that the students can use during their task and learning steps. A questionnaire set up by the researcher to get a consensus among the six faculty members in relation to confirm this theory-based process. The present study is qualitative with respect to the research question. The MATLAB software is used for designing the flowcharts.

3.6. Data analysis

A part of data analysis is related to designing a questionnaire which will be filled in according to the researcher's intention. Another part is related analyzing the flowchart data based on 'Computational Cognitive' model of visual attention. Finally, the results are prepared to be discussed. For validation and design of the questionnaire, the researcher uses Smart Survey.

\subsection{Raters}

Six faculty members in Ruskin/London university with over 15 years of teaching experience were selected to agree with the designed instructional diagrams related to certain theories and to confirm this training flowchart.

\section{Results}

\subsection{Results of the Questionnaire}

The following numbers are according to the professors' responses and comments to the questionnaire which are tabulated in table 4.1.

Table 4.1 Faculty members' responses to the questionnaire

\begin{tabular}{|c|c|c|c|c|}
\hline \multirow{2}{*}{ Questions } & \multicolumn{2}{|c|}{ Negative(>.50) } & \multicolumn{2}{|c|}{ Positive(<.50) } \\
\hline & Frequency & Percentage & Percentage & Percentage \\
\hline $\begin{array}{l}\text { 1. Is it necessary that use such flowchart for identification } \\
\text { of your students' perception and motivation, as well as } \\
\text { other educational goals? }\end{array}$ & 0 & 0.00 & 2 & 0.95 \\
\hline $\begin{array}{l}\text { 2. would you like to know how to use your students from } \\
\text { this designed diagram? }\end{array}$ & 0 & 0.00 & 1 & 0.75 \\
\hline $\begin{array}{l}\text { 3. Does this designed algorithm help your teaching and } \\
\text { improve students' theory-based perception? }\end{array}$ & 0 & 0.00 & 2 & 0.100 \\
\hline $\begin{array}{l}\text { 4. Can this diagrammatic outline be as an important way } \\
\text { for teachers to enter it in an instructional curriculum? }\end{array}$ & 0 & 0.00 & 1 & 0.85 \\
\hline $\begin{array}{l}\text { 5. Do you believe that such diagrams have significant } \\
\text { effect on improving learners' learning/teaching? }\end{array}$ & 0 & 0.00 & 2 & 0.95 \\
\hline $\begin{array}{l}\text { 6. Do you believe that students are more interested to } \\
\text { participate in a given situation whit this procedural } \\
\text { design? }\end{array}$ & 0 & 0.00 & 1 & 0.85 \\
\hline
\end{tabular}

The questionnaire indicated that the students can acquire favorite consequence by this instructional diagrammatic outline.

According to the questionnaire results, the professors' responses in relation to the training theory -based diagram could help them to find out their students' motivation and perception for student self-study. For agreement, confidence, and correct of these designs in the present study, the researchers used the particular question of the research. 


\subsection{Results of the Designed Instructional Flowchart}

Table 4.2 The correlation of six faculty members

\begin{tabular}{|ll|r|r|}
\hline & \multicolumn{1}{|c|}{ Gender } & \multicolumn{1}{c|}{ Reponses } \\
\hline Gender & Pearson Correlation & 1 & .449 \\
& Sig. (2-tailed) & & .372 \\
& $\mathrm{~N}$ & 6 & 6 \\
\hline Responses & Pearson Correlation & .449 & 1 \\
& Sig. (2-tailed) & .372 & \\
& $\mathrm{~N}$ & 6 & 6 \\
\hline
\end{tabular}

As the correlation results indicated, the correlation was significant between the raters. The suggestion of the combinatory flowchart of the researcher:

- Combination of transformational generative grammar theory and Input hypothesis theory

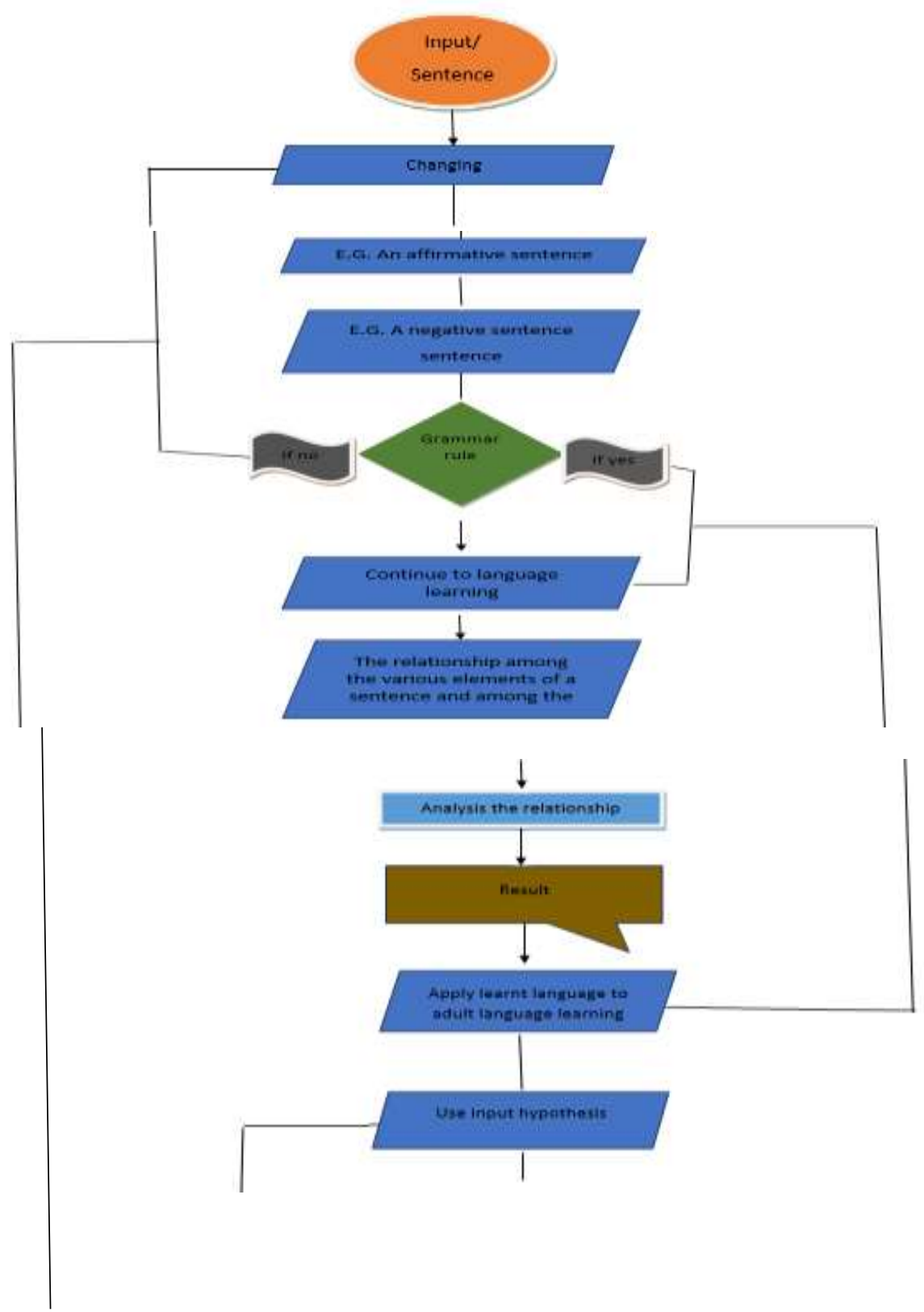




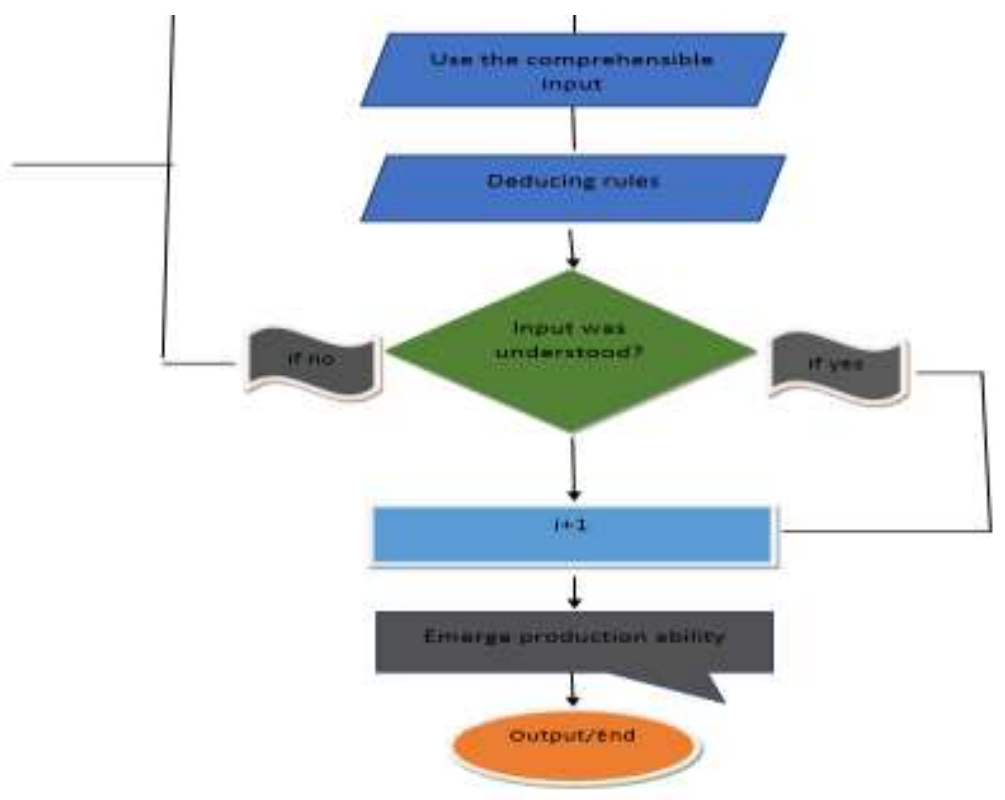

Figure 4.1 The combinatory designed proposed algorithm by the researcher

\section{Discussion}

The present study aimed at designing an instructional flowchart/diagram for 10 teaching theory which is a need for ELT. 'Computational Cognitive Model' of visual attention was used in using the designed flowchart and utilizing it practically. Theory-based design contributes to the researchers discover the goals they should aim to perform in order to focusing on the choice of a proper theory and managing body of it in his/her work.

The question of the present study as the primary manifestation is restated for checking the study improvement. Teachers and students' inadequacy in transferring theory into practice could be acceptable based on 'Computational Cognitive' model of visual attention and the result acquired of the study. Theory holds learning best through strategizing a model or method according to an innovative and novel outline. This proposed design is synchronic with each type of theory framework.

Two standard ways for representing constituent structure were specified by Borsley (1999). The first was a labelled tree diagram which was a set of positions or nodes labelled based on syntactic theory. The second way was a labelled bracketing. They looked at how students can investigate the constituent structure of sentences or phrases.

Algorithmic solutions can be the mainstay of a training approach. The Ohio program moves between education and training steps of within the projects. Learning concepts and principles under control of their application in the projects and students are beyond the algorithmic method. Strategic knowledge can be gained during the interactions with other learners which the primary purpose for continuing education may be to improve problem-solving abilities (Duffy and Kirkley, 2008).

The model used of this study was reviewed with the entire theory flowcharts, and the process was followed to display a new track for gravitating students toward using the tentative designed algorithmic theory-based work. Boring issues, ineffective teaching methods, and lack of time to attend classes are among the discussions that English language students face. This designed way is a new and meaningful way for those who love to learn and interest in taking a different look at the theory-based world. "computational modeling appears to be the most promising approach in many respects and offers more flexibility and expressive power than other approaches" (Meng and Sen, 2017, p: 1).

\section{Conclusion}

\subsection{Findings}

The results of the study showed that this algorithmic designed outline as a strategy was best for helping students' motivation and perception to be progressed in ELT. This study aims to convince students for using a procedural and technical way in their tasks. Utilization of this proposed and applied design can be a popular and efficient one among ELT learners. It can enable learners to choose the educational models suitable with their plan. The significance of the proposed design which make it distinctive from other studies is that it enhances students' interest and motivation to use it as a basic outline in training track.

The advantages of this study:

- No extra work

- No repeating

- High speed 
- Manage processing of information easily

- Patterning

- Switching the part

- Increasing the part as an innovative effect

- Noticing the shortcomings of the theory

- Simplification of the theory concept

- debugging

This educational outline is proposed for larger project with complicated content. Learners can apply this new design to their task and use it in performing other parts of a given task simultaneously. Meng and Sen (2017) stated that CCM properly works in figuring out which process is the best. Then, the researcher could have enough potential in choice of the most appropriate theories from the rest to combine them.

\subsection{Implications}

Experiences have students can affect their theory learning. kinds of strategies available to learners as optimal like the used way in the present study can help them in ELT. Formal instruction without awareness of its underlying logic is distinct from more general abilities to process information or operate intelligently. The design and selection of teaching theory algorithms must take into account not only the nature of the subject matter but also how students learn.

6.3. Suggestions for Further Study

These educational algorithms can be implemented in software and other educational programs to be accessible to learners. They can be combined with other programs and projects to have the more profitable implementation. This technique can be effective in learners' self-regulation and self-efficacy discussions. Teaching-Learning-Based Optimization and project-based instruction can be a good guide for these kinds of studies as well. The algorithmic ways to display the overall template of the task can use the inquiry-based method.

\section{References}

Borsley, R. D. (1999). Syntactic Theory: A Unified Approach. Oxford University Press Inc.

Branch, R., \& Merrill, M. D. (2011). Characteristics of instructional design models. In R. A. Reiser \& J.V. Dempsey (Eds.), Trends and issues in instructional design and technology (pp. 8-16). Upper Saddle River, NJ: Merrill-Prentice Hall.

Brooks, N. H. (1960). Language and Language Learning: Theory and Practice. Harcourt, Brace.

Brown, H. D. (2000). Principles of Language Learning and Teaching. White Plains, NY: Longman.

Bruner, J. (1960). The process of Education. Cambridge, MA: Harvard University Press.

Burlton, R. (2015). Tackling Risk Management and Process Improvement at the Same Time. Retrieved from: https://www.linkedin.com/pulse/tackling-risk-management-process-improvement-same-time-roger-burlton

Cameron, L. (2001). Teaching Languages to Young Learners. Cambridge: Cambridge University Press.

Çelik, S., \& Erbay, S. (2013). Cultural perspectives of Turkish ELT coursebooks: Do standardized teaching texts incorporate intercultural features? Education and Science, 38(167), 336-351.

Corder, S. P. (1967). The significance of learners' errors. International Review of Applied Linguistics. 4, $161-169$.

De Pisapia, N., Repovs, G., \& Braver, T. (2008). Computational models of attention and cognitive control. In R. Sun (Ed.), The Cambridge Handbook of Computational Psychology (pp. 422-450). New York: Cambridge University Press.

Dubey, A., Keller, F., \& Sturt, P. (2008). A probabilistic corpus-based model of syntactic parallelism. Cognition, 109(3), 326344.

Duffy, T. M., \& Kirkley, J. R. (2008). Learner-Centered Theory and Practice in Distance Education. Taylor and Francis eLibrary. Indiana University, London.

Enever, J. (Ed.) (2011). ELLiE: Early language learning in Europe. London: British Council.

Gane, C. (1972). Managing the training function: Using instructional technology and systems concepts. Industrial and Commercial Training,4(4), 192-193, https://doi.org/10.1108/eb003212

Itti, L., Koch, C., \& Niebur, E. (1998). A model of saliency-based visual attention for rapid scene analysis. IEEE Transactions on Pattern Analysis and Machine Intelligence, 20(11), 1254-1259.

Koch, C., \& Ullman, S. (1985). Shifts in selective visual attention: towards the underlying neural circuitry. Human Neurobiology, 4(4), 219-227.

Krashen, S. D. (1985). The input hypothesis: Issues and implications. London: Longman.

Larsen-Freeman, D. (2013). Complexity theory: A new way to think. Revista Brasileira de Linguística Aplicada, 13(2), 369373 ,

Lawrence-Lightfoot, S., \& Davis, J. H. (1997). The art and science of portraiture. San Francisco: Jossey-Bass.

McLeod, S. A. (2018). Skinner - operant conditioning. Simply Psychology: Psychology. This workis licensed under a Creative Commons Attribution-Noncommercial-No Derivative Works 3.0 Unported License. https://www.simplypsychology.org/operant-conditioning.html

Meng, R., \& Sen, A. (2017). What is a Computational Cognitive Model? Retrieved from https://lucid.wisc.edu/what-is-a-computational-cognitive-model/ 
Ohlsson, S. (2008). Computational models of skill acquisition. In R. Sun (Ed.), The Cambridge Handbook of Computational Psychology (pp. 359-395). New York: Cambridge University Press.

Quora I. 2020. What are the main uses for a flowchart? Retrieved from: https://www.quora.com /What-are-the-main-uses-fora-flowchart

Robinson, Bryan J., Clara I. López Rodríguez \& María I. Tercedor. (2006). Self-assessment in translator training. Perspectives:Studies in Translatology 14(2), 115-138. http://www.multilingualmatters.net/pst/014/0115/pst0140115.pdf

Skinner, B. F. (1957). Verbal behavior. New York: Appleton-Century-Crofts. DOI:10.1037/11256000

SmartDraw, LLC. (1994-2019). Diagrams. Retrieved from: https://www.smartdraw.com/ /flowchart/

Snaider, J., McCall, R., \& Franklin, S. (2012). Time Production and representation in a conceptual and computational cognitive model. Cognitive Systems Research. 13(1), 59-71. https://doi.org/10.1016/j.cogsys.2010.10.004

Wittwer, J., Nückles, M., \& Renkl, A. (2010). Using a diagnosis-based approach to individualize instructional explanations in computer-mediated communication. Educational Psychology Review, 22, 9-23. doi:10.1007/s10648-010-9118-7.

\section{Notes}

\footnotetext{
${ }^{1}$ https://creately.com/blog/

${ }^{2}$ Smartdraw- https://www.smartdraw.com/flowchart/flowchart-types.htm

${ }^{3} \mathrm{https} / / / \mathrm{www}$.questionmark.com/content/creating-questions

${ }^{4}$ https://www.smartsurvey.co.uk/questionnaire-design
} 